\title{
A methodology to compare risk management (RM) systems for the application and validation of specific threats in public transportation
}

\author{
C. Baumgarten, F. Brauner, C. Bentler, O. A. Mudimu \\ \& A. Lechleuthner \\ Institute of Rescue Engineering and Civil Protection, \\ Cologne University of Applied Sciences, Germany
}

\begin{abstract}
Background: Different events affecting public transportation systems such as the Madrid bomb attacks in 2004 have exposed the vulnerability of open and complex infrastructure. Providers have to deal with these threats and prepare to prevent and respond. For a systematic identification and assessment of threats, a variety of appropriate risk management (RM) systems can be chosen. To choose an appropriate RM system for a public transportation system, a comparison is needed. Therefore, the providers have to define self-assessment criteria based on local requirements to get reliable results.

Aim: Most international RM systems are based on qualitative descriptions making it difficult to extract and determine such criteria. In fact, no comparison can currently be done between different qualitatively described RM systems. One solution to obtain reliable comparative results is the quantification of qualitative statements. This research shows an assignment of numerical values for qualitative criteria to make a comparison possible.

Method: The comparison is based on adaptation of a use-value analysis that accomplishes the requirements of public transportation systems. It compares different decision alternatives, especially if there are no quantitative criteria. Qualitative criteria are categorized and assigned to each pre-defined target compliance factors connecting with numerical values. Additionally, the prioritisation of qualitative criteria is determined with weighting coefficients.
\end{abstract}


Results: The combination of weighting coefficient and target compliance factor helps to establish reliable results in a relative comparison. The use-value analysis is defined by assessment criteria for risk and threat detection, effort of implementation and support, and quality of RM results.

Conclusion: Public transportation providers can use this method using their local requirement and assessment criteria to find an appropriate RM system. Still, the application of the use-value analysis provides reliable information about the suitability of different RM systems, but no further information about the effect of the systems.

Keywords: assessment criteria, comparison, critical infrastructure, public transportation, risk management, use-value analysis.

\section{Introduction}

Critical infrastructure such as public transportation systems play a major role in today's society. Not only the high number of daily passenger transfers, the different links and interdependencies of public transportation to other critical infrastructure and sectors are also a vulnerable factor of the society and industry. Threats and disturbances influence the system and can cause consequences in multi-dimensional ways such as, societal functions, health, safety and security, economic or, social well-being of people [1]. For example, the terrorist attacks in Tokyo (1995), Madrid (2004), London (2005) and Mumbai (2006) exposed the vulnerability of complicated open systems.

This is the reason why public transportation providers try to protect their systems as much as possible to ensure cost-effective usage of security measures.

To identify and assess possible financial risks, RM systems were invented for the financial sector. Today, the implementation of RM systems in critical infrastructure is of paramount importance [2]. RM systems allow structural identification, analysis, assessment and controlling of risks and measures. A huge variety of different RM methods can be found in the literature using different techniques and approaches. Security experts of providers have to decide which RM system fits their company and gives best results for local requirements.

The challenge in comparing RM systems is that qualitative statements cannot be quantified for numerical comparison [3]. It is the reason why a reliable assessment of RM systems is unthinkable, unless qualitative statements can be transferred into quantified data. In 2007, the ENISA published a functional comparison method in the IT-sector by scoring the processes according to qualitative statements [4], but the possibility of weighting the processes to self-requirements is not included in the method.

\section{Methodology}

A reliable methodology for comparing RM systems needs basic requirements. Most RM systems have a lot of qualitative information, which cannot be compared in a quantitative way for contrasting juxtaposition and accurate result. 
The challenge is that qualitatively influenced variables cannot quantify directly [3], because text modules, which are available in most RM guidelines, provide no basis for this process. Therefore, a method, which can transfer the qualitative information into numerical values for enabling required comparing results, is needed. Furthermore, a self-information prioritisation method for public transportation providers should be introduced, which would create opportunity to contribute self-perceptions or specific requirements.

The comparison method of ENISA, which is mentioned in the introduction, uses a benchmark system to transfer qualitative information in a RM approach. This allows comparison between qualitative statements and information, but prioritisation of requirements is not included. So, this method does not seem suitable for application in this specific sector. A solution is to adapt a methodology of project management and implement the requirements in a reliable comparison [3]. The methodology is an adapted use-value analysis for comparing various options without quantitative, especially numerical basis of decision-making. Based on weighting of different assessment criteria, there is an opportunity for prioritisation. For each RM system option, a value of benefit will set and compute in relative comparison with other options. So, the public transportation providers can select a RM system according their own needs.

Figure 1 shows the procedure of this adapted methodology. The steps will be described in the following chapters without examples, which will be illustrated in chapter 3.

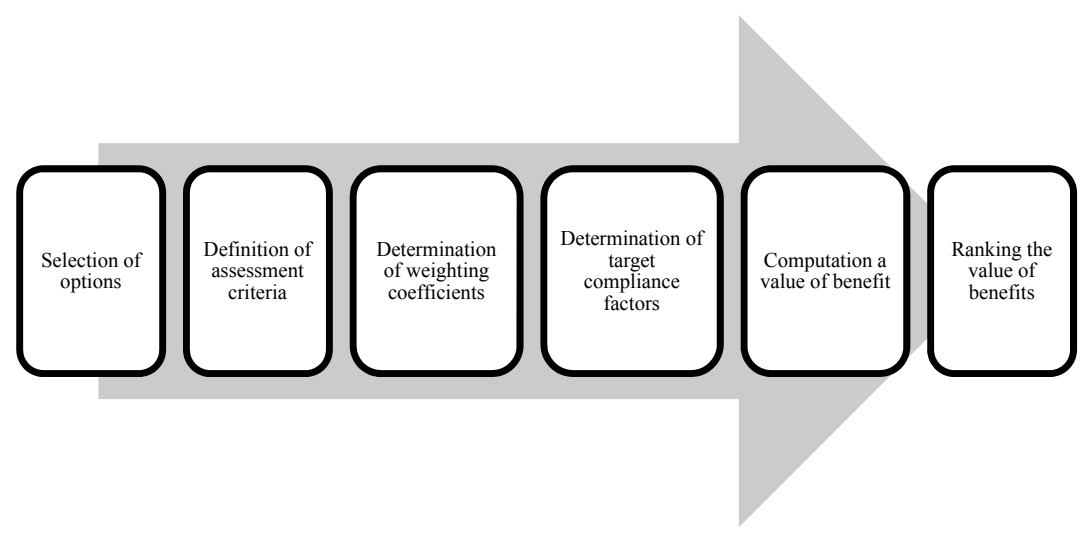

Figure 1: Approach for comparing RM systems (source: authors).

\subsection{Selection of options}

In the first step, the public transportation providers have to choose selective options of RM systems, which could be implemented in their own public transportation systems. No criteria are necessary for this selection, because it is independent of any requirement. At this point, it is possible that providers put any RM system, e.g. in context of critical infrastructure, in the pool of selection options for decision making. 


\subsection{Definition of assessment criteria}

In the second step, the public transportation providers define assessment criteria for evaluating the suitable RM system for implementation and application. It is very important that appropriate criteria related to decision-making should only be defined. It is advisable to define not more than five criteria for the implementation of this methodology, [3].

\subsection{Determination of weighting coefficients}

A very important requirement for this methodology is the opportunity to prioritise the assessment criteria in an individual way. Therefore, weighting coefficients will refer any assessment criterion to give criteria a different emphasis in computation with the value of benefit for all selection options.

In this step, each defined assessment criteria will be contrasted with other defined assessment criteria and set in a comparison matrix. At this point, the providers have to decide which assessment criterion is more important for an assessment and decision in context of selecting a suitable RM system. When an assessment criterion is more important than another criterion, it is scored with a value of two. A value of zero is assigned complementary. For an equal importance, the assessment criteria are scored with a value of one. By dividing the subtotal of an assessment criterion with the total sum, weighting coefficient for each assessment criterion can be determined. The weighting coefficient reflects the amount of an assessment criterion for the comprehensive decision and is one part of computation of the benefit value.

Table 1 shows an example for determining weighting coefficients $(W C)$ with four assessment criteria $(C)$. The values can be defined by public transportation providers for any implementation of this methodology in context of the assessment criteria. The highest numerical weighting coefficient means the most significant assessment criterion for decision-making.

Table 1: Example for determination of weighting coefficients (source: authors).

\begin{tabular}{|c|c|c|c|c|c|c|c|}
\hline $\begin{array}{c}\text { Assessment } \\
\text { criteria }\end{array}$ & ù & $u^{2}$ & $u^{m}$ & $U^{+}$ & $\begin{array}{l}\frac{\pi}{\pi} \\
0 \\
0 \\
0\end{array}$ & \multicolumn{2}{|c|}{$\begin{array}{l}\text { Weighting } \\
\text { coefficients }\end{array}$} \\
\hline$C_{I}$ & & 2 & 2 & 2 & 6 & 0,500 & $W C_{l}$ \\
\hline$C_{2}$ & 0 & & 1 & 0 & 1 & 0,083 & $W C_{2}$ \\
\hline$C_{3}$ & 0 & 1 & & 0 & 1 & 0,083 & $W C_{3}$ \\
\hline$C_{4}$ & 0 & 2 & 2 & & 4 & 0,333 & $W C_{4}$ \\
\hline & & & & Total & 12 & 1 & \\
\hline
\end{tabular}




\subsection{Determination of target compliance factors}

The fourth step deals with the description of defined assessment criteria. For all assessment criteria, target compliances have to be determined in a qualitative written form. These target compliances are deposited with numerical target compliance factors. The target compliance for an assessment criterion shows how a RM system accomplishes this criterion. The higher the target compliance of a RM system for each assessment criterion is, the higher the numerical target compliance factor should be defined. The points system scale can be chosen by own estimation and is independent of any standard set by the public transportation providers' decision. The more information is available for a RM system, the finer the scale can be created.

\subsection{Computation a value of benefit}

Then, a sub-value of benefit ( $\left.X_{\text {option }}\right)$ for each RM system in context of one assessment criterion $(C)$ can be computed based on the weighting factor $(W C)$ of this assessment criterion and the target compliance factor (TCF) as a function of compliance target. Formula 1 shows an abstract consideration for this computation [6].

$$
X_{\text {Option }}\left(C_{1}, \ldots, C_{n}\right)=\sum_{i=1}^{n}\left(W C_{i} * T C F_{\text {option }}\left(C_{i}\right)\right)
$$

After the computation, the sub-value of benefit ( $X_{\text {option }}$ ) for a RM system in relation to an assessment criterion, the addition of values enables the determination of a value of benefit [3] for this special RM system (see table 2).

Table 2: Example for computing value of benefit (source: authors).

\begin{tabular}{|l|l|l|c|}
\cline { 3 - 4 } \multicolumn{2}{c|}{} & \multicolumn{2}{c|}{ Option $_{\mathrm{n}}$} \\
\hline$C_{i}$ & $W C_{i}$ & $T C F\left(C_{i}\right)$ & $X_{(i)}$ \\
\hline$C_{1}$ & $W C_{1}$ & $T C F\left(C_{1}\right)$ & $W C_{1} * T C F\left(C_{1}\right)$ \\
\hline$C_{2}$ & $W C_{2}$ & $T C F\left(C_{2}\right)$ & $W C_{2} * T C F\left(C_{2}\right)$ \\
\hline$C_{3}$ & $W C_{3}$ & $T C F\left(C_{3}\right)$ & $W C_{3} * T C F\left(C_{3}\right)$ \\
\hline$C_{4}$ & $W C_{4}$ & $T C F\left(C_{4}\right)$ & $W C_{4} * T C F\left(C_{4}\right)$ \\
\hline & & \multicolumn{2}{|c}{ Value of benefit ${ }_{\mathrm{n}}=\sum_{\mathrm{i}=1}^{4} \mathrm{X}_{(\mathrm{i})}$} \\
\cline { 3 - 4 } & & \multicolumn{2}{c}{}
\end{tabular}

\subsection{Ranking the value of benefits}

The computed value of benefit for each RM system, which is part of the defined selection options, allows a relative comparison of these values. So, in the last step of this methodology, all values of benefit of RM systems can be ranked for a numerical relative comparison. The highest ranked RM system is the most 
suitable for implementation and application in own public transportation system. This step allows public transportation providers to compare different RM systems with qualitatively described information for decision making.

\section{Implementation}

In this chapter, the theoretical description of the methodology is explained through an example. Public transportation providers have to identify their input, output and required resources of their processes [7]. In context of quality management, these data should be available. For implementation by a public transportation provider, assessment criteria related to their system have to be defined. For example, the following criteria can be defined as:

- Detection: Public transportation systems deal with specific threats and risks according to the structural requirements of their system. Therefore, it is important that a RM system is able to detect and treat these threats and risks. Lack of detection can cause serious consequences in the decision making process.

- Effort: The effort for implementing a RM system is important for the process activity and the organisation itself. Internal and external resources can be used for the RM system. For this reason, effort is an assessment criterion for providers to manage their capacities.

- Support: Depending on the RM system, different kinds of support are provided to the end-user. This assessment criterion judges the support to the end-user through instructions, recommendations and assistance guidelines.

- Quality of results: The results of RM systems may differ in form of the level of detail. This quality assessment criterion judges the outcome of the RM system according to information for the end-user.

This list of examples can extend to the level needed by the public transportation providers. So, in addition, costs, lead time or compatibility might also be criteria of importance and might be included.

According to chapter 2.3, the public transportation providers have to determine their weighting factors between each criterion. In this example, the 'threat/risk detection' and the 'quality of results' have the highest value and are scored with two points because (according to the author's opinion), only captured threat and risk can be processed in a RM system and lead to results. Also, the authors set the 'quality of results' on highest score as a consequence of the threat detection and 'effort' and 'support' are scored with one point. The authors make clear, weighting factors have to be adapted according to the self-preferences of the company so results of this comparison method also differ.

In the next step (see chapter 2.4), the target compliance factors have to be defined. Therefore, the aim has to be defined in detail for the different assessment criteria. In example four, classifications are set and scored with the numbers of 1 to 4 points (see table 3). For the assessment criterion 'threat/risk detection' a percental scale is possible, while for effort, support and results a percental scale is impossible and qualitative statements are used. 
Table 3: Determination of target compliance for assessment criteria (source: authors).

\begin{tabular}{|c|c|c|c|c|}
\hline $\begin{array}{l}\text { Assessment } \\
\text { criteria }\end{array}$ & $\begin{array}{c}\text { Target } \\
\text { compliance } \\
1 \text { point }\end{array}$ & $\begin{array}{c}\text { Target } \\
\text { compliance } \\
2 \text { points }\end{array}$ & $\begin{array}{c}\text { Target } \\
\text { compliance } \\
3 \text { points }\end{array}$ & $\begin{array}{c}\text { Target } \\
\text { compliance } \\
4 \text { points }\end{array}$ \\
\hline Detection & $\begin{array}{l}\text { detection of less } \\
\text { than } 70 \% \text { of all } \\
\text { threats and risks } \\
\text { in public } \\
\text { transportation }\end{array}$ & $\begin{array}{l}\text { detection of at } \\
\text { least } 70 \% \text { of all } \\
\text { threats and risks } \\
\text { in public } \\
\text { transportation }\end{array}$ & $\begin{array}{l}\text { detection of at } \\
\text { least } 80 \% \text { of all } \\
\text { threats and risks } \\
\text { in public } \\
\text { transportation }\end{array}$ & $\begin{array}{l}\text { detection of at } \\
\text { least } 90 \% \text { of all } \\
\text { threats and risks } \\
\text { in public } \\
\text { transportation }\end{array}$ \\
\hline Effort & very high & high & medial & small \\
\hline Support & $\begin{array}{c}\text { short description } \\
\text { of RM system }\end{array}$ & $\begin{array}{c}\text { detailed } \\
\text { description of } \\
\text { RM system }\end{array}$ & $\begin{array}{l}\text { detailed } \\
\text { description of } \\
\text { RM system incl. } \\
\text { examples and } \\
\text { guidelines }\end{array}$ & $\begin{array}{l}\text { detailed } \\
\text { description of } \\
\text { RM system incl. } \\
\text { examples and } \\
\text { guidelines and } \\
\text { templates and } \\
\text { supporting } \\
\text { documents }\end{array}$ \\
\hline $\begin{array}{l}\text { Quality of } \\
\text { results }\end{array}$ & risk assessment & $\begin{array}{l}\text { detailed risk } \\
\text { assessment }\end{array}$ & $\begin{array}{l}\text { detailed risk } \\
\text { assessment } \\
\text { according to } \\
\text { specific } \\
\text { additional } \\
\text { parameters }\end{array}$ & $\begin{array}{l}\text { detailed risk } \\
\text { assessment } \\
\text { according to } \\
\text { specific } \\
\text { additional } \\
\text { parameters } \\
\text { including } \\
\text { critical } \\
\text { processes, } \\
\text { vulnerability } \\
\text { intensity and } \\
\text { resilience, etc. }\end{array}$ \\
\hline
\end{tabular}

The visualised possible target compliance is a basis for the implementation of this adapted use-value analysis by public transportation providers. The target compliance and the target compliance factors can be chosen freely by users of this methodology as described before.

\section{Results}

To generate results, five different RM systems, which can be used in public transportation systems, are going to be compared. These approaches are standard in the field of critical infrastructure. At this point, any available RM systems can be used. The authors chose two German systems, one of the Association of German Transport Companies (VDV [8]) and one of the German Federal Ministry of the Interior (BMI [9]). For a comprehensive reflection, international systems of the Danish Emergency Management Agency (DEMA [10]), Public Safety Canada [11] and a European research project (COUNTERACT [12]) are added. In this paper, these different RM systems cannot be described in detail, 
but have to be read separately as needed. The exact determination of appropriate target compliance factors cannot be described in detail as well because that is not part of this methodology paper.

Table 4 shows the target compliance of RM systems based on a study research report of the author [13] produced in the year 2013. This German study investigated the RM systems in detail to determine target compliance factors dependent on their assessment criteria.

Table 4: Target compliance factors for RM system (source: authors).

\begin{tabular}{|c|c|c|c|c|c|}
\cline { 2 - 6 } \multicolumn{1}{c|}{} & \multicolumn{5}{|c|}{ RM system } \\
\hline Assessment criteria & VDV & BMI & DEMA & COUNTERACT & $\begin{array}{c}\text { Public } \\
\text { Safety } \\
\text { Canada }\end{array}$ \\
\hline Detection & 4 points & 4 points & 2 points & 1 point & 2 points \\
\hline Effort & 4 points & 1 point & 3 points & 2 points & 2 points \\
\hline Support & 1 point & 3 points & 4 points & 4 points & 2 points \\
\hline Quality of results & 1 point & 4 points & 3 points & 3 points & 3 points \\
\hline
\end{tabular}

The visualized estimation is part of the foundation for computing the value of benefits of a RM system. In connection with weighting factors based on an assignment of value in chapter 3 and the mathematical computation in table 1, all parameters are available for creating results. As a result, a multiplication of the weighting factors $(W C)$ and target compliance factors $(T C F)$ in context of an assessment criteria leads to the sub-values of benefits $(X)$ (see table 2). At this point, the summation of all sub-values of benefits for each assessment criteria creates the value of benefit $(V o B)$ for the related RM system. So each RM system receives a numerical value and a value of benefit which makes a relatively reliable comparison based on the numerical values.

Table 5 shows the final computation results for the values of benefits of RM systems. The highest value represents the best suitable RM system for the authors used public transportation system according to individual preferences. This table gives the public transportation provider a reliable and transparent basis of decision-making for choosing a RM system from a pool of possible systems.

The results of this adapted use-value analysis depend on the subjective assessment of the end-users. Although quantification is used to make qualitative statements comparable, the right allocation cannot always be guaranteed. The use of quantified assessment criteria is helpful to check the allocation. For the 'detection' criterion, the quantification can be ensured, while the other assessment criteria are based on an estimation of the end-users. Basically, all assessment criteria shall be defined and described completely to get reliable estimations and results. Even minor changes can change the results in the end. Additionally, the use-values must be relatively comparable to reach an absolute 
significance. Whether a RM system is adequately applicable for a critical infrastructure or not, needs further tests and cannot be assessed with this methodology finally.

Table 5: Values of benefits for RM systems (source: authors).

\begin{tabular}{|c|c|c|c|c|c|c|c|c|c|c|c|}
\hline \multirow[b]{3}{*}{ Assessment criteria } & \multirow[b]{3}{*}{$W C$} & \multicolumn{10}{|c|}{ RM system } \\
\hline & & \multicolumn{2}{|c|}{ VDV } & \multicolumn{2}{|c|}{ BMI } & \multicolumn{2}{|c|}{ DEMA } & \multicolumn{2}{|c|}{ COUNTERACT } & \multicolumn{2}{|c|}{$\begin{array}{c}\text { Public Safety } \\
\text { Canada }\end{array}$} \\
\hline & & $T C F$ & $X$ & $T C F$ & $X$ & $T C F$ & $X$ & $T C F$ & $X$ & $T C F$ & $X$ \\
\hline Detection & 0,500 & 4 & 2,000 & 4 & 2,000 & 2 & 1,000 & 1 & 0,500 & 2 & 1,000 \\
\hline Effort & 0,083 & 4 & 0,333 & 1 & 0,083 & 3 & 0,250 & 2 & 0,167 & 2 & 0,167 \\
\hline Support & 0,083 & 1 & 0,083 & 3 & 0,250 & 4 & 0,333 & 4 & 0,333 & 2 & 0,167 \\
\hline Quality of results & 0,333 & 1 & 0,333 & 4 & 1,333 & 3 & 1,000 & 3 & 1,000 & 3 & 1,000 \\
\hline & & $V o B=$ & 2,750 & $V O B=$ & 3,667 & $V o B=$ & 2,583 & $V o B=$ & 2,000 & $V o B=$ & 2,333 \\
\hline
\end{tabular}

\section{Conclusion}

RM systems are important, especially in the field of critical infrastructure such as public transportation systems where a failure has multidimensional effects [14]. Every provider has to find an eligible approach which fits the organisational requirements and captures all relevant risks and threats. The data acquisition is difficult for quantitative RM approaches, but the results are reliable. That is the reason why quantitative RM approaches should be preferred. Unfortunately, no such comprehensive approach for critical infrastructure can be found in literature.

This paper shows existing qualitative RM systems, which can be used for public transportation services. The use-value analysis is an appropriate method to compare RM systems. Even then, there are no quantitative assessment criteria. Considering the limitations, a numerical comparison of qualitative statements can be executed. In the end, a use-value ranking displays the results of the best RM system according to the assessment criteria. Therefore, every end-user, e.g. public transportation, or other critical infrastructure providers, has to set its own assessment criteria implying organisational requirements as well as weighting coefficients.

\section{Funding}

The Institute of Rescue Engineering and Civil Protection at the Cologne University of Applied Sciences performs research in the field of critical infrastructure. This research is funded in a national research project called 
"RiKoV" by the German Federal Ministry of Education and Research, which deals with an integrated risk management system for terrorist attacks in public transportation systems.

\section{References}

[1] The Council of the European Union, COUNCIL DIRECTIVE 2008/114/EC of 8 December, 2008 on the identification and designation of European critical infrastructures and the assessment of the need to improve their protection. Official Journal of the European Union, L 345, pp. 75-82, 23.12.2008.

[2] Flammini, F., Critical Infrastructure Security, WIT Press: Southampton, pp. xv, 2012.

[3] Zimmermann, J., Rick, J. \& Stark, C., Projektplanung. Modelle, Methoden, Management, Springer: Berlin, pp. 27-28, 2006.

[4] European Network and Information Security Agency (ENISA), Methodology for evaluating usage and comparison of risk assessment and risk management items (deliverable 2), 1, Heraklion, 2007.

[5] Niklas, C., Mehr Entscheidungssicherheit mit der Nutzwertanalyse. Projekt Magazin - Das Fachportal für Projektmanagement, 23, p. 1-5, 2002.

[6] Kenter, I.M., Laborskript - Methode: Nutzwertanalyse, p. 4, Bremen University of Applied Sciences, Bremen.

[7] Koch, S., Einführung in das Prozessmanagement von Geschäftsprozessen - Six Sigma, Kaizen und TQM, Springer: Berlin, pp. 71, 2010.

[8] VDV AG Security, VDV-Sicherheitsleitfaden für ÖPNV-Unternehmen Safety und Security, Köln, 2008.

[9] German Federal Ministry of the Interior (BMI), Protecting Critical Infrastructures - Risk and Crisis Management (A guide for companies and government authorities), 1, Berlin, 2008.

[10] Danish Emergency Management Agency, DEMA's Model for Risk and Vulnerability Analysis - Introduction and User Guide, Birkerød, 2006.

[11] Public Safety Canada, Risk Management Guide for Critical Infrastructure Sectors, 1, 2010.

[12] COUNTERACT Consortium, PT4: Generic Guidelines for Conducting Risk Assessment in Public Transport Networks - Final Report 4 (deliverable 3), Brussels, 2009.

[13] Baumgarten, C., A comparison of risk management approaches in the field of critical infrastructures with applications and validation using the example of public transportation (bachelor thesis), Cologne University of Applied Sciences, Cologne, 2013.

[14] Macaulay, T., Critical Infrastructure - Understanding Its Component Parts, Vulnerabilities, Operating Risk, and Interdependencies, CRC Press: Boca Raton, pp. 1-24, 2009. 